\title{
Gamma Glutamyl Transpeptidase Measurement
}

National Cancer Institute

\section{Source}

National Cancer Institute. Gamma Glutamyl Transpeptidase Measurement. NCI

Thesaurus. Code C64847.

A quantitative measurement of the amount of gamma g lutamyl transpeptidase present in a sample. 